department of cultural activities will concentrate on the human implications of development. The main focus in 1965-6 will be on artistic creation. Studies and research on the creative process and the re-examination of traditional values and forms of expression are new chapters in a programme that includes such initiatives as a survey on the special situation of African intellectuals; support for a Festival of African Art in 1966 at Dakar; industrial aesthetics, handicrafts, and folk art; and the introduction of cinema education at the university level.

\title{
The Ashanti Research Project
}

THE proceedings of a preparatory conference on the Ashanti Research Project, held in May I 963 at the Kwame Nkrumah University of Science and Technology, Kumasi, and organized and sponsored by the Institute of African Studies, University of Ghana, Legon, have recently been published. The project involves research in various fields, relating to the development of society and culture over the area which, historically, fell within the Ashanti sphere of influence. The fields to be covered include history; government; social and economic institutions; music, literature, and art; archaeology and traditional architecture. It is estimated that the project will cover a period of three years. A generous grant from UNESCO for the year 1964 has enabled the Institute of African Studies of the University of Ghana to finance the following: the purchase of microfilms of materials from European archives relating to Ashanti, and their transcription; the translation from Dutch, Danish, German, Arabic, and Hausa of texts relating to Ashanti; the collection of Ashanti stool histories; the transcription of important Ashanti constitutional cases (from the archives of the Kumasi divisional court); the collection of Arabic manuscripts relating to the history of Ashanti; and the collection of texts of Akan Drum language. These collections are being deposited in the Institute and will be made available to bona fide scholars. The Institute will be glad to hear from scholars wishing to associate themselves with the Ashanti Research Project, and hopes to produce periodically a news bulletin which will include notes on work in progress.

\section{University of Ibadan: Workshop on the Teaching of African History}

THE Institute of Education, University of Ibadan, in association with the History Department, recently held a Workshop on the teaching of African history from 14 to 29 March. This was made possible by a generous grant from the Carnegie Corporation. The purpose of the Workshop was to orientate and inform teams of inspectors, training-college tutors, and secondary-school teachers concerned with the introduction of the two new syllabuses of the West African Examinations Council on African History-West Africa from A.D. 1000 to the present, and Africa in the nineteenth and twentieth centuries. The teams, each of about six people, came from all four English-speaking countries of West Africa and undertook assignments in the field of African history teaching. Demonstration lessons given in the International School of the Institute of Education were a special feature of the Workshop.

\section{Research Chair of Archaeology at the University of Ibadan, Nigeria}

UNTIL 1963 practically all archaeological research in Nigeria had been undertaken either by individuals coming in from outside, like Frobenius, or, more recently, by the Federal Department of Antiquities, whose former Director, Mr. Bernard Fagg, is well known.

Efforts to establish archaeology in the University of Ibadan had failed for lack of money until the Institute of African Studies was set up there by a generous grant from the Rockefeller Foundation in 1962, and, within it, by means of another generous grant from the 